\title{
TWO MORE FAMILIES WITH CARDIOMEGALY
}

\author{
BY \\ MAURICE CAMPBELL AND MARGARET TURNER-WARWICK \\ From Guy's Hospital, University College Hospital, and the Institute of Cardiology \\ Received September 10, 1955
}

When the well-recognized causes of cardiac hypertrophy have been excluded there is still a group of patients in whom large hearts are found: the diagnosis may have been made on routine examination or following the investigation of cardiac failure or arrhythmia. Elster et al. (1955) gave clinical and post-mortem details of ten cases of rapidly fatal cardiac failure associated with a large heart, and discussed the possible ætiology.

A familial incidence of cardiac enlargement has not, however, been reported often. It is known to occur in von Gierke's disease and in Friedreich's ataxia, both of which have a familial incidence. In von Gierke's disease the condition is always associated with disturbances of carbohydrate metabolism and usually with hepatomegaly, and is almost invariably diagnosed in childhood. Occasionally the heart alone is affected (Pompe, 1932): it becomes large, partial or complete heart block often developes, and cardiac failure may be the cause of death. Histological study reveals glycogen deposits in the myocardium (von Gierke, 1929; Ellis and Payne, 1936).

In Friedreich's ataxia, Evans and Wright (1942) found striking electrocardiographic abnormality in 12 of 38 patients with neurological features. It was more common to find the heart involved in those with a family history of the disease. Cardiac enlargement was not evident clinically though it could be demonstrated on fluoroscopy; there was complete heart block in two patients and flattening or inversion of the $T$ waves in the limb leads in nine. Histological examination of the myocardium showed muscle fibre hypertrophy with patchy fibrosis, and the Purkinje fibres also were separated by fibrous tissue (Russell, 1946). We have not found among the families with Friedreich's ataxia any members who show cardiac involvement only without neurological features.

There remains a group of patients showing a familial incidence of cardiac enlargement with arrhythmia but without associated disease. Evans (1949) reported nine cases with cardiomegaly of unknown ætiology, of which three occurred in one family and two in another, and four were isolated cases. In four of the five familial cases cardiac disease was not discovered until adult life. The enlargement of the heart was chiefly due to the left ventricle, the blood pressure was always normal, and a triple rhythm was frequently heard. The changes of rhythm included paroxysmal tachycardia, auricular fibrillation and flutter, and atrio-ventricular and bundle-branch block. Two patients died, two months and four years after the onset of syncopal attacks. Histological examination revealed great hypertrophy of the muscle fibres of the myocardium with interstitial fibrosis, but without gross cellular infiltration or any fatty replacement of muscle fibres: although glycogen was found in one instance, Evans thought that these were not cases of van Gierke's disease.

We have not been able to find reports of many other families similarly affected, though one has been described by Gaunt and Lecutier (1956). The condition of the heart in the family reported by Paulley et al. (1956) was attributed to toxoplasmosis, but this was not certain.

The condition is sufficiently uncommon to warrant this account of two families: the first includes a mother and son only though many others had died early in life; in the second a slow heart rate, due to heart block in two members and to sinus bradycardia with bundle-branch block in the third, is known to have been present in three generations, and other members of the family had some evidence of cardiac abnormality and two died at an early age. 
notched and bifid and the P-R interval was $0.24 \mathrm{sec}$. His hæmoglobin was 110 per cent with a red blood count of 5.7 million. After a period of rest in hospital he returned to work.

Some months later he was admitted into the West London Hospital under Dr. G. L. S. Konstam, under whose care he had been earlier, and died in a prolonged paroxysm of tachycardia. Dr. Konstam has informed us that his case was reported by Blanshard (1953) with an account of the necropsy which we have therefore abridged.

Necropsy. The heart weighed $820 \mathrm{~g} .:$ it was pale with many petechial hæmorrhages. Both ventricles were enlarged, the wall of the right being $5 \mathrm{~mm}$. thick compared with the enormously hypertrophied left ventricle which was $25 \mathrm{~mm}$. thick. There was fibrosis towards the apex anteriorly and a fibrous patch 25 by $12 \mathrm{~mm}$. in the wall of the right ventricle, and diffuse fibrosis in the lower part of the septum. The mitral valve was normal with some roughening on the margin. The other valves were normal. The coronary arteries were normal but small compared with the massive left ventricle. The lungs were congested with patches of broncho-pneumonia. The liver was congested with nutmeg changes. The spleen weighed $370 \mathrm{~g}$. There were no other abnormalities.

On microscopical examination, the muscle fibres were hypertrophied and there was dense patchy fibrosis of the myocardium in all the parts examined; no Aschoff bodies were seen. There was scattered cellular infiltrate consisting of lymphocytes and mononuclear cells (Fig. 2, Blanshard, 1953). The sections were examined by Dr. Harrison and his views are quoted in the discussion.

Case 2, aged 29 at death. G.D., the mother of Case 1, her only child, had been in the National Heart Hospital under Dr. Parsons-Smith eighteen years before. She was thought to have had rheumatic fever 
when she was 15 and was in bed for five months. Nevertheless, she led an active life, doing all her housework without symptoms, until a rather sudden onset of dyspnœa when she was 28 , followed quickly by congestive failure two months before admission. She had a large globular heart (c.t.r. $68 \%$ ) that seemed to involve all chambers, the left more than the right (Fig. 2). She had a double second sound that was thudding in character, and was thought to have mitral stenosis though a faint diastolic murmur was heard only irregularly and the systolic murmur was not loud. Her blood pressure was 105/68. She had an even more remarkable picture of bundle-branch block with a QRS of $0.18 \mathrm{sec}$. (Fig. 3). Her Wassermann reaction was negative.

After leaving hospital she got on all right for a year when she was readmitted with the same symptoms and severe giddiness. The signs were as before except that the heart was even larger (c.t.r. $71 \%$ ) and the cardiogram of lower voltage with the QRS width increased to $0.22 \mathrm{sec}$. (Fig. 3). Again she responded to treatment and seemed fairly well, but died, aged 29, quite suddenly while being examined two days before she was due to go home. Unfortunately there was no necropsy.
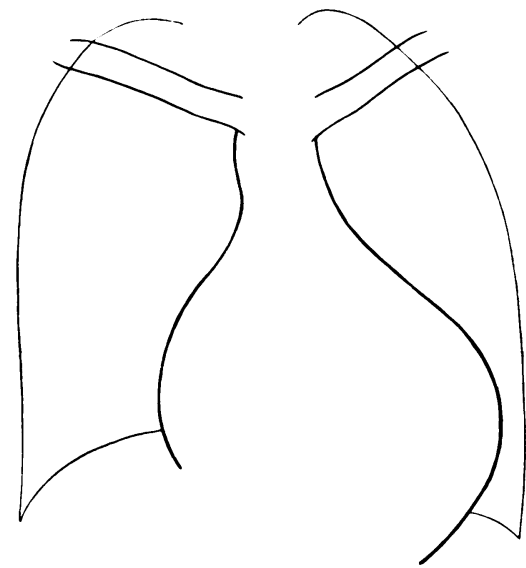

FIG. 2.-Orthodiagram of the heart of Case 2, showing great enlargement with a cardiothoracic ratio of 68 per cent.

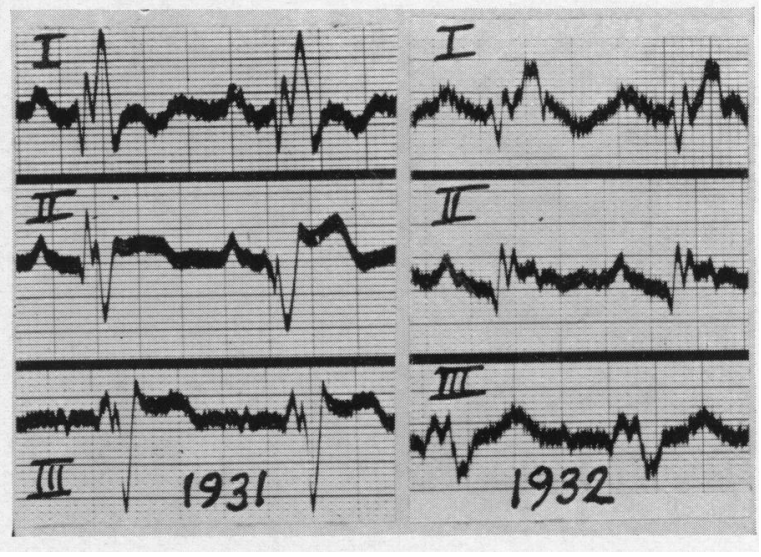

FIG. 3.-Standard lead electrocardiograms from Case 2, showing bundle-branch block with widening QRS complexes, in 1931 a year before, and in 1932 just before, her sudden death.

Other Members of the Family. When Case 1 was in hospital, only one of the twelve brothers and sisters of his mother (Case 2) was still living. Blanshard (1953) states that 8 of these 12 had died with heart disease, four between the ages and 23 and 40 and four in infancy: he does not seem to have been aware of the death of Case 2, possibly because when Case 1 was in hospital all references to her were avoided, as we were so impressed by the resemblance of the two and so fearful that Case 1 would die suddenly as his mother had.

The father and mother of Case 2 had lived to 76 and 78 and had no history of heart disease, but an aunt was said to have dropped dead in the street when she was 19 years of age.

\section{The SeCond Family}

Case 3, aged 36 at death. A. M. had jaundice at the age of 17 , and was seen by one of us with his mother (Case 4): no cardiovascular abnormality was found. He continued to lead a full and active life, playing rugger for his public school and while in the army. He had dysentery three times, but no other serious illnesses.

In 1950, when he was 36 , he was admitted to University College Hospital under the care of Dr. J. C. Hawksley, complaining of attacks of unconsciousness for three months. His first attack came while he was sitting down, and he gave a vivid description of a feeling like a blush spreading upward over his body followed by profuse sweating; he then became dizzy and unable to think clearly, and finally fell to the ground unconscious. During the next three months he had three similar attacks, each lasting a few minutes.

On examination, he was intelligent and well built. His pulse was regular at 40 a minute and the blood pressure was 128/70. There were no signs of congestive failure either on admission or later. The heart 
sounds were normal; there were no murmurs and no triple rhythm. The apex beat was $11.5 \mathrm{~cm}$. from the mid-line and thrusting in quality: X-ray examination showed a large heart, especially the left ventricle, the cardiothoracic ratio being 55 per cent (Fig. 4A). The liver and spleen were not palpable, and there were no neurological or skeletal abnormalities. The hæmoglobin was 98 per cent, the blood count normal, and

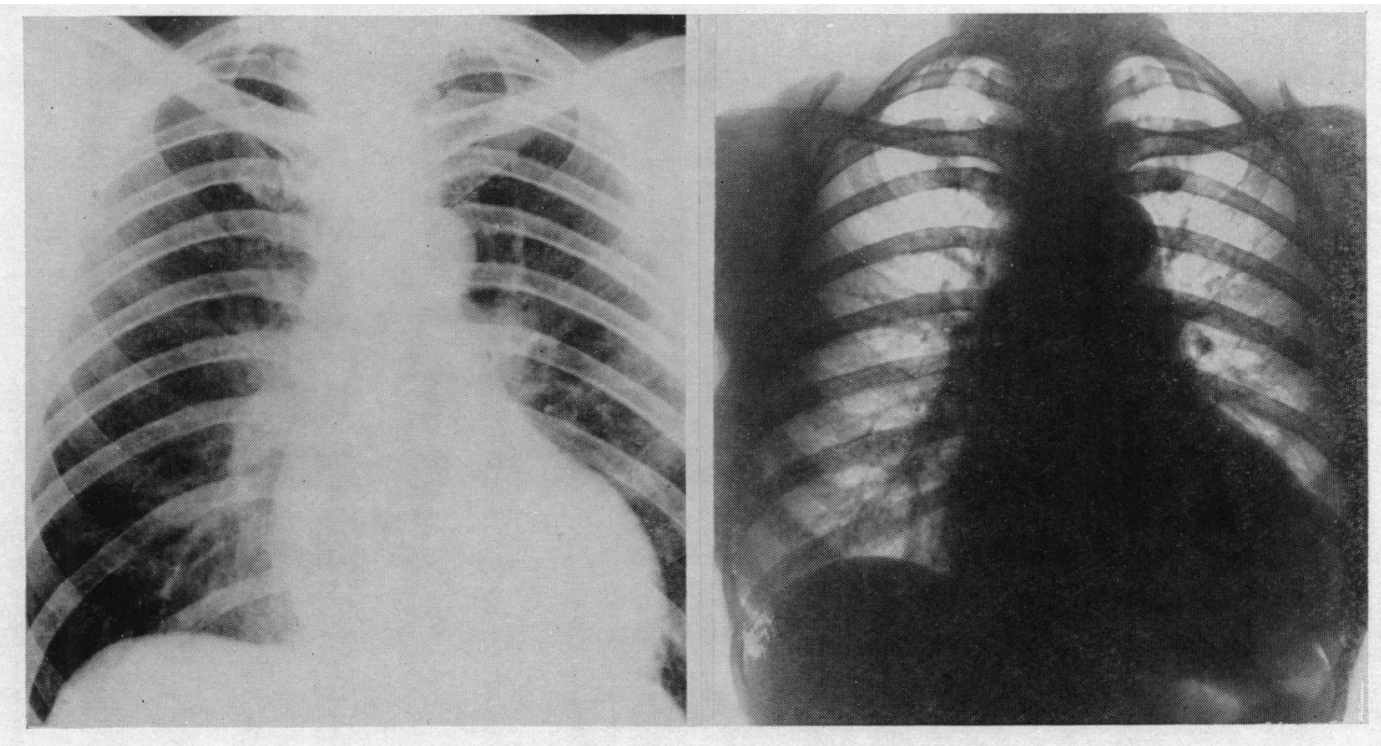

A

B

FIG. 4.-Teleradiograms, showing enlargement, especially of the left ventricle. (A) Case 3. The cardiothoracic ratio was only 55 per cent but the heart weighed 1050 grammes. (B) Case 4, aged 66, the mother of Case 3. A very large heart with a cardiothoracic ratio of 62 per cent $(17 / 27.6 \mathrm{~cm}$.). Although she now has hypertension with a blood pressure of $200 / 100$ we think that most of the enlargement is due to the myocardial changes as the blood pressure was still 140/80 when she was 60 , in 1950 .

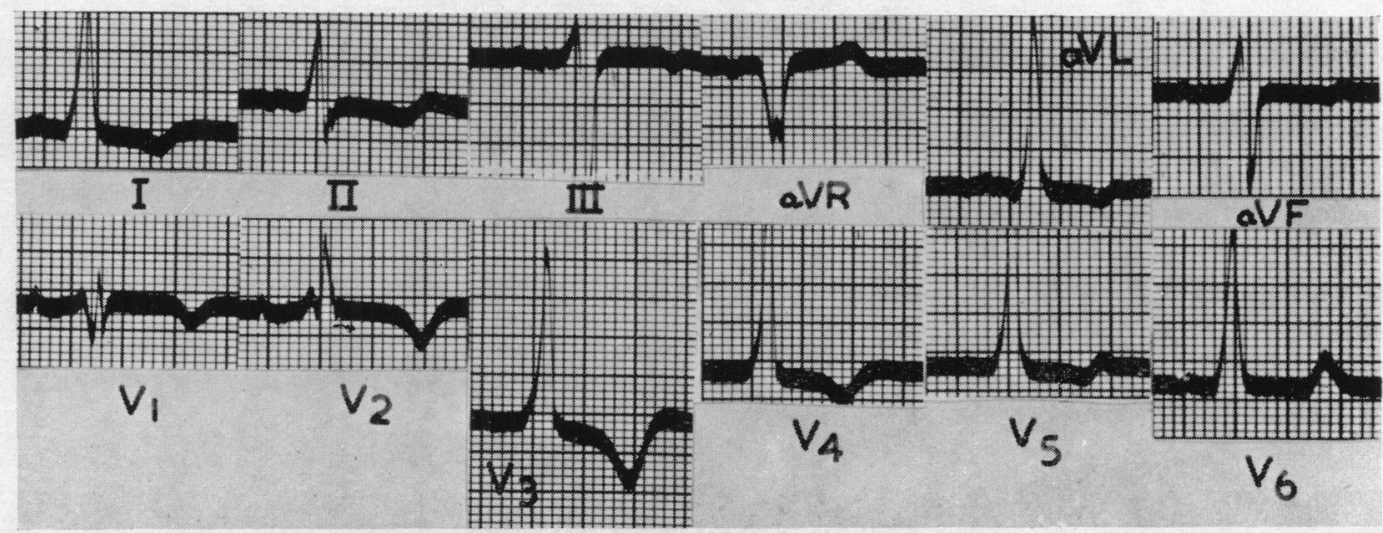

FIG. 5.-Electrocardiogram between attacks. Rate 35 a minute. Sinus rhythm. Left axis deviation. $\mathrm{T}$ wave inversion maximal in V3. Case $3(7 / 10 / 50)$.

the sedimentation rate $14 \mathrm{~mm}$. in an hour. The Wassermann and Kahn reactions were negative as they had been in 1932 .

Between attacks he showed either a sinus or nodal bradycardia, and during attacks of faintness, varying high degrees of A-V block, sometimes complete. On admission there was sinus bradycardia at 35 a minute with occasional nodal and ventricular extrasystoles. There was left axis deviation, a small $\mathrm{W}$ complex in V1, and inverted $\mathrm{T}$ waves maximal in V3 (P-R, $0.2 \mathrm{sec}$. and QRS, 0.12 sec.) (Fig. 5), and later there was 
nodal rhythm with complete left bundle-branch block (Fig. 6B). During the first attack of faintness recorded there was an idiopathic ventricular rhythm at a rate of 35 a minute (Fig. 6A). During some later attacks the ventricular rate fell to about 12 a minute, due to a high degree of A-V block (8:1), the atrial rate being 100 a minute (Fig. $6 \mathrm{C}$ ). During another attack an atrial rate of 35 a minute with $2: 1 \mathrm{~A}-\mathrm{V}$ block was observed (Fig. 6D).

The onset of bradycardia between 8 and 10 beats a minute was sudden and lasted about thirty minutes. The recovery to a rate of about 50 a minute took place gradually over a period of fifteen minutes; occasionally, but much less often, there was sudden doubling or halving of the rate. The syncopal attacks which were often accompanied by pain increased in frequency and severity until the fatal one two months after his admission. Intravenous atropine was given to relieve them, but tended to induce A-V block. Intramuscular ephedrine had no effect on the heart rate. The fatal syncopal attack had lasted thirty minutes

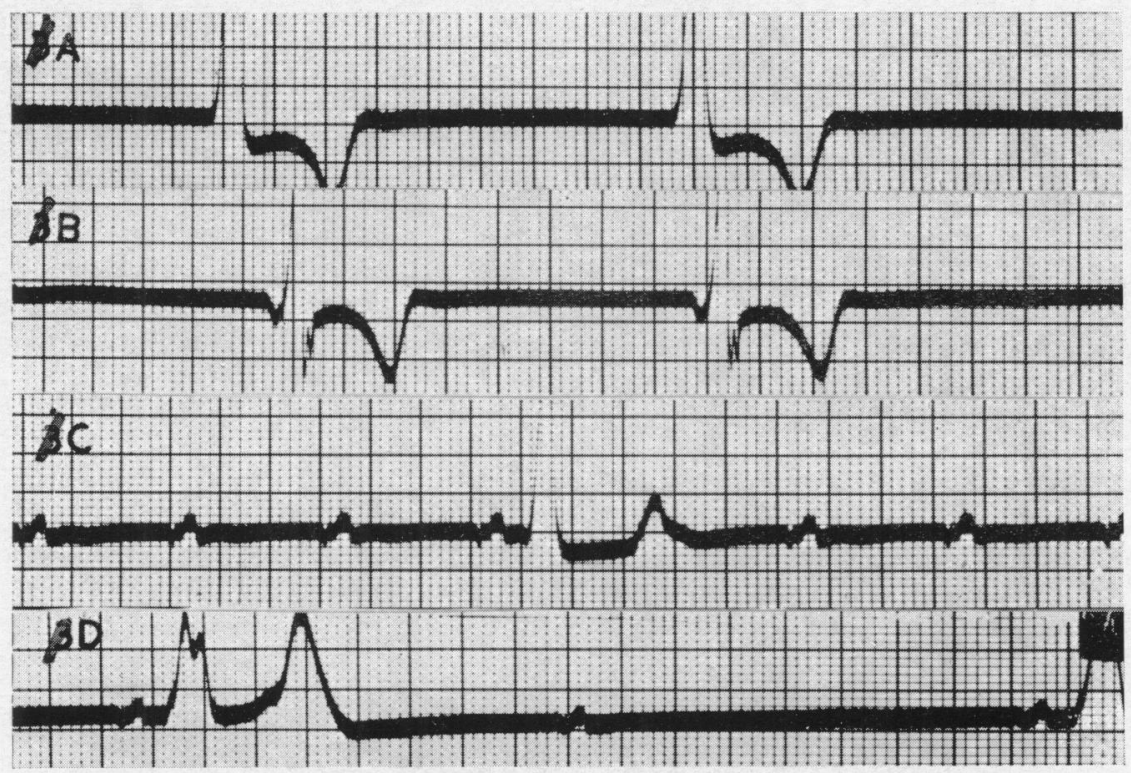

FIG. 6.-Electrocardiograms (lead II) during and between attacks. (A) During an attack. Recording considered to represent idiopathic ventricular rhythm at a regular rate of 35 a minute with complete heart block $(9 / 10 / 50)$. (B) Between attacks. Nodal bradycardia, rate 39 a minute. $P$ inverted and $P-R$ of $0 \cdot 1$ sec. $(21 / 11 / 50)$. (C) During attack. Atrial rate 94 a minute. A longer strip of this recording showed $6: 1$ and $8: 1 \mathrm{~A}-\mathrm{V}$ block $(22 / 11 / 50)$. (D) During attack. Sinus bradycardia, atrial rate 37 a minute with $2: 1 \mathrm{~A}-\mathrm{V}$ block $(22 / 11 / 50)$. Case 3 .

when the heart stopped beating and neither intravenous coramine nor subcutaneous and intracardiac adrenaline were of any avail.

Necropsy. The heart weighed $1050 \mathrm{~g}$. The pericardium over the right atrium showed thickening due to old pericarditis. The gross enlargement was chiefly due to the massive left ventricle, the walls of which exceeded $25 \mathrm{~mm}$. in thickness (Fig. 7). The endocardium and valves were normal, and there was no evidence of rheumatic disease. The atrial walls were thickened. The sinu-atrial node was visible through the endocardium as a yellowish mass, and the atrio-ventricular node was similarly represented although not visible except on the cut surface. The coronary vessels showed some medial thickening, but no narrowing; they were, however, disproportionately small in relation to the enormous ventricle (cf. Case 1).

Histology. The left ventricular myocardial fibres were hypertrophied; some showed central clear spaces and some œdema, but there was no fatty change or fibrosis. Central clear spaces were present also in the hypertrophied atrial muscle; these were not globular as in fat, nor basophilic as in glycogen. Most of the atrial hydropic fibres were devoid of nuclei (Fig. 8). Fibres in the S-A and A-V nodes were grossly hydropic and lay in interstitial fat and fibrous tissue. A hyalinized scar was also present in the A-V node. The hydropic areas contained no substance that could be identified by the usual histochemical methods: 


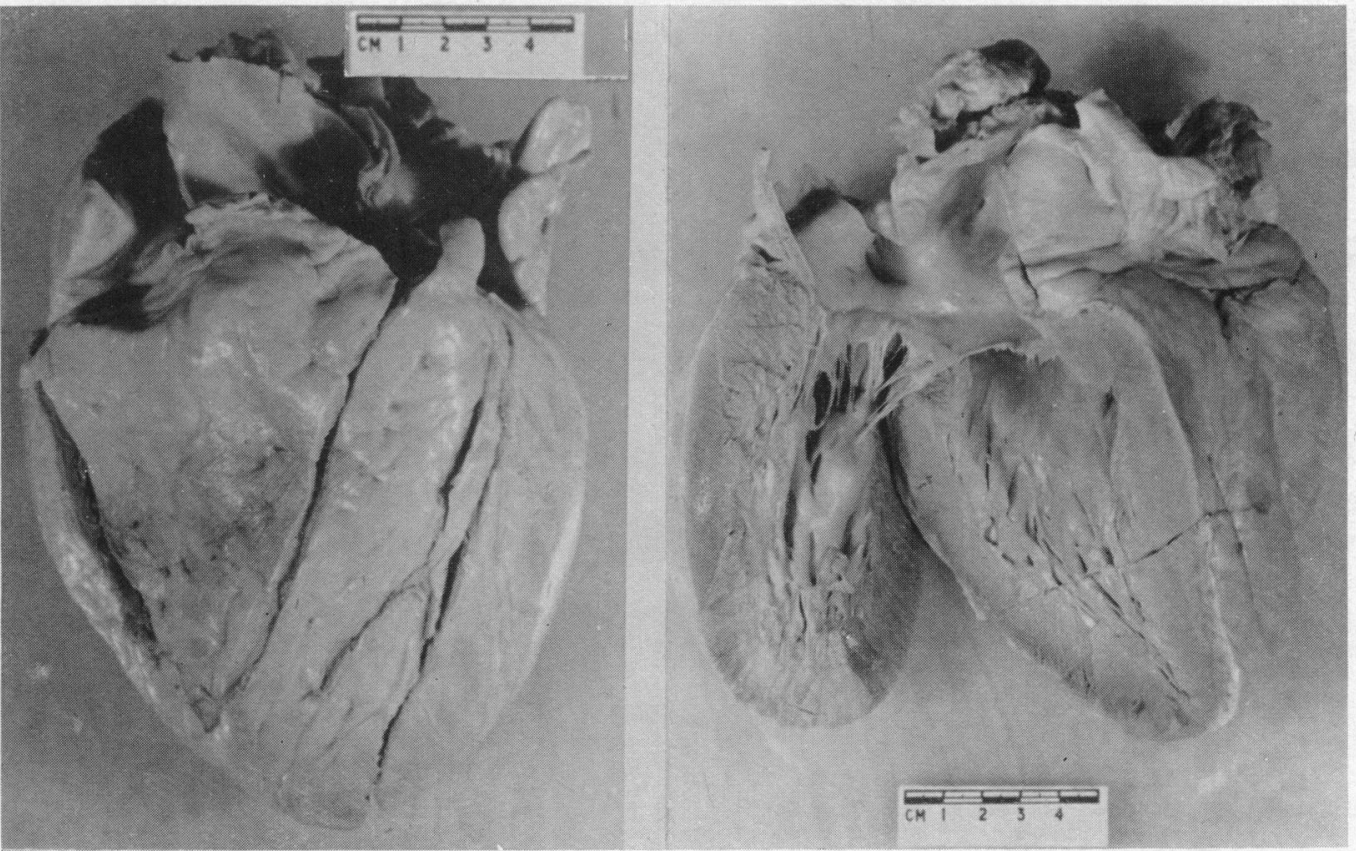

FIG. 7.-Macroscopic appearance of the heart that weighed 1050 grammes. The mitral valve was normal at necropsy but was torn during dissection. Case 3 .

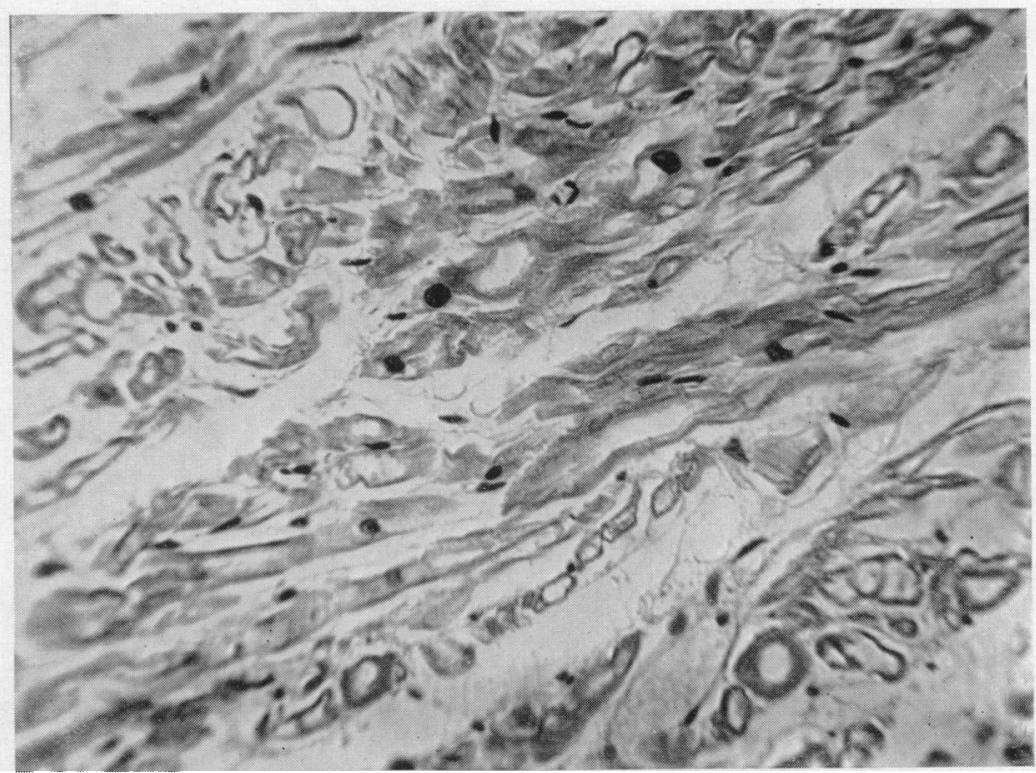

Fig. 8.-Microscopical appearance of muscle of left atrium (magnification $\times 285$ ), showing vacuolation and absence of nuclei in the majority of muscle fibres. Case 3. 
no glycogen could be demonstrated by the periodic acid Schiff reaction, and the only fat demonstrated by Scharlach red lay in the fat cells between the distorted muscle fibres.

The Children of Case 3. His two children, a boy now aged 10 and a girl aged 7, were examined in 1950: the boy was found to have an apical systolic murmur and radiographic evidence of slight enlargement of the heart, but no abnormality was found in the girl. Both children have been examined again in 1956 and show no clinical, radiographic, or electrocardiographic evidence of heart disease.

Case 4, now aged 66. G. M. gave no history of rheumatic fever. When she was 23, her only child (Case 3) was born. About three years later she began to feel tired and breathless and had attacks of faintness though she was rarely unconscious. Her doctor found she had a slow pulse, generally 45-50, but once as slow as 25 a minute.

She was first seen by one of us in 1928 when she was 38 and there was little change in her condition during the next ten years. She had to lead a quiet life and suffered from faintness and extreme fatigue if she did too much, and was always too breathless to lead the active life she had led till she was 25 years old. Treatment with thyroid did not help her and there was no suggestion of myxœdema. The position and force of the apex beat suggested a larger heart than the cardiothoracic ratio of 53 per cent (cf. Case 3). There was a systolic murmur at the apex which was constant and widely conducted; mitral regurgitation was suspected, but no diastolic murmur nor any other evidence of mitral stenosis was found. Her blood pressure was about $140 / 80$.

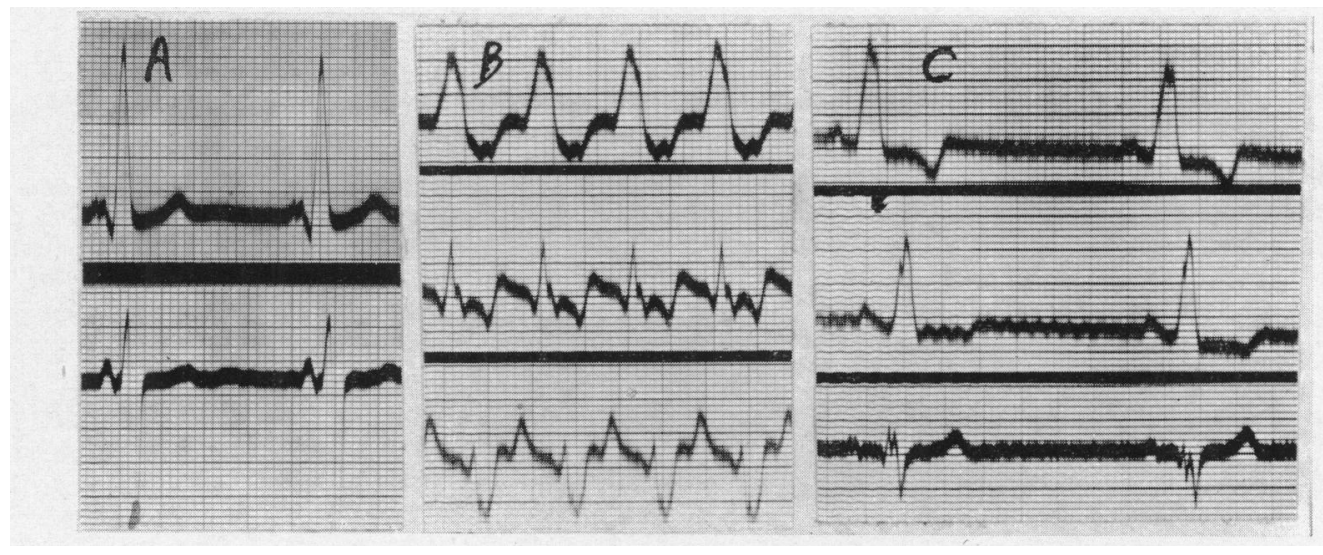

FIG. 9.-Electrocardiograms of Case 4. (A) Leads I and III in 1929; (B) auricular flutter with 2:1 block in 1940; and (C) sinus bradycardia and bundle-branch block later in 1940 .

During these ten years her heart rate was between 32 and 60 , most often between 40 and 48 a minute, and she felt better when it was faster and often felt faint when it was slower. The electrocardiogram showed sinus bradycardia (range 40-60) with sinus arrhythmia and occasional ventricular extrasystoles, and left axis deviation with no inversion of the T waves (Fig. 9A). The short P-R interval, 0.11 sec., and the wide QRS, 0.11 sec. and sometimes 0.14 sec., suggested the Wolff-Parkinson-White syndrome, but in 1937 when for the first time in a dozen records the P-R interval was $0 \cdot 16 \mathrm{sec}$., QRS was equally wide.

In 1940 she was admitted with paroxysmal tachycardia at a rate of 150 a minute, probably auricular flutter with 2:1 block (Fig. 9B), which stopped on the fifth day after 3 drachms of digitalis in four days. For the next three weeks her pulse was charted generally between 32 and 48 a minute, and a cardiogram showed sinus bradycardia at 40 a minute with a P-R interval of $0.20 \mathrm{sec}$. and left bundle-branch block (QRS 0.14 sec.); T was inverted in lead I for the first time (Fig. 9C).

She was seen again in 1945 and in 1950 and had been getting on well except for six further paroxysms of tachycardia, two lasting for three and five days. The physical signs and heart rate were unchanged but the heart was larger. In $1945 \mathrm{~T} 1$ was again upright, but in 1950 there was classical left bundle-branch block with T inversion in leads I and V7 (QRS, 0.16 sec.; Fig. 10).

She is now 66 and is not much changed, except that her blood pressure has risen from 140/80 to 220/110. The rate is generally about $40-50$ a minute and the systolic murmur and bundle-branch block are as before, but the heart has become larger (Fig. 4B): we do not attribute much of the increase to the high blood pressure as this was still $140 / 80$ in 1950 . 


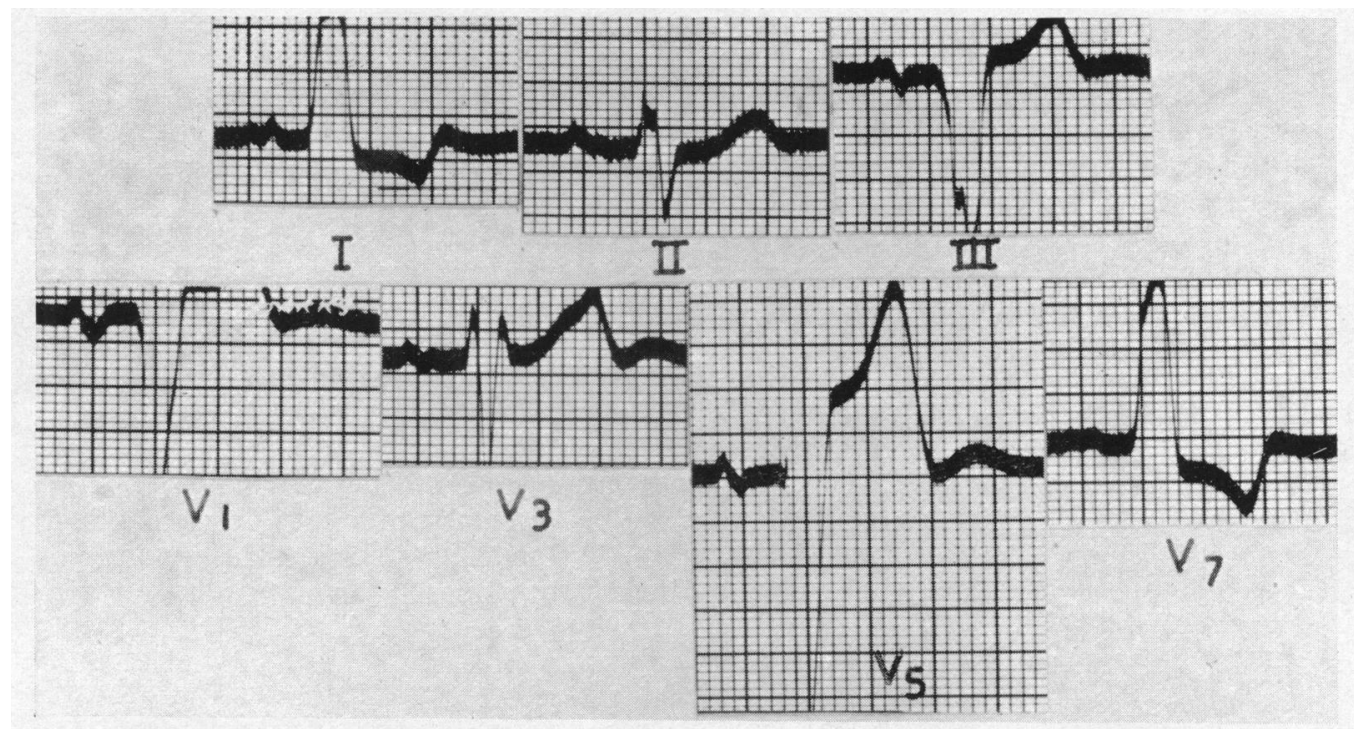

FIG. 10.-Standard and unipolar leads from Case 4 in 1950. There has been no significant change between 1950 and 1956.

Note on the Husband of Case 4. Three years after Case 4 was first seen, her husband was found to have syphilitic aortic incompetence and he died with heart failure three years later. There was nothing to suggest that the heart lesion of Case 4 was syphilitic and her Wassermann and Kahn reactions were negative both in 1932 and in 1940, and this was also true of their son (Case 3). In view of these negative findings and the absence of any evidence of syphilis in the necropsy of Case 3, it is unlikely that this played any part.

Case 5. One of three sisters of Case 4, had lone auricular fibrillation that reverted to normal within 17 days. Nothing else abnormal was found about her heart so this may be no more than a chance finding.

Earlier Generations. Case 6. The mother of Cases 4 and 5 lived till she was 69 but suffered with her heart for several years and the diagnosis on the death certificate was "heart failure and complete heart block"; we do not know how long the heart block had been present.

Three of her sisters were said to have had heart disease. Two lived to 70 and 84 , but the former had been an invalid for years and was said to have a slow heart: the third is said to have died before she was 20 with heart disease; she was in Guy's Hospital as a girl in 1880, but the notes are not available and she was indexed as disease of the spine.

In the previous generation, the mother of Case 6 died, also with heart disease, while she was still in her thirties; she was said to have been in Guy's Hospital, but we have been unable to find the case notes. We have no proof that these members of earlier generations suffered from the same heart condition but it is likely: heart block, slow heart rates, and early deaths without evidence of rheumatic heart disease were more frequent than would be expected.

\section{DisCUSSION}

In our first family a mother and son, both with very large hearts and bundle-branch block, died suddenly at an early age, one year and three years respectively after the onset of symptoms. In our second family a young man (Case 3) and his maternal grandmother had heart block and his mother (Case 4) had sinus bradycardia and bundle-branch block. The duration of symptoms in the grandmother is not known: in the mother they started when she was 28 and still persist 38 years later, but the son died suddenly at the age of 36 , within five months of his first Stokes-Adams attack.

Cases 3 and 4 demonstrate the extreme variability of survival times, irrespective of the initial cardiographic and radiological findings: early and sudden death is more usual, as in most of the 
cases reported by Evans (1949) who suggested that the prognosis was poor when major cardiographic changes and a large heart were present in a young person.

Hearts weighing over 1000 grammes are relatively uncommon in any condition, but the heart weighed $1134 \mathrm{~g}$. in Case 1 of Evans, $1050 \mathrm{~g}$. in our Case 3,820 g. in our Case 1, and $737 \mathrm{~g}$. in Case 1 of Gaunt and Lecutier.

Among the cases reported by Evans (1949) and by Gaunt and Lecutier (1956) extrasystoles, paroxysmal tachycardia, auricular fibrillation, bradycardia, heart block, and bundle-branch block were all fairly common, and both these authors stress the high voltage of the QRS complexes, as in some of our cases. Bradycardia seemed common among the cases reported by Evans and heart block was present in Case 1 of Gaunt and Lecutier and from time to time in their Case 3, who had Stokes-Adams attacks. It seems likely that our Case 5 suffered from the same familial disorder as no other cause for auricular fibrillation was found, but it may have been fortuitous.

There was no evidence of any of the neurological features of Friedreich's ataxia in any members of these families, but few of them were specifically examined.

The ætiology of this condition remains obscure in spite of the histological data available. A diffuse degenerative process affecting the entire thickness of the myocardium appears to be the fundamental lesion: the muscle fibres are hypertrophied but the most striking feature is the vacuolation of muscle fibres and of the conducting system. The histological picture in our Case 3 differs from that described by Evans (1949) in that fibrous tissue is almost completely absent and the hydropic change is greater. This vacuolation of the muscle fibres was also a main feature in the necropsy of Gaunt and Lecutier (1956). Patchy fibrosis was, however, present in our Case 1 and the sections were examined by Dr. C. V. Harrison who reported "This is an example of smouldering almost healed myocarditis. The fibrosis is not of the type or distribution that one sees in either rheumatism or ischæmia and there is endarteritis in small arteries and still some cellular infiltration in the interstitial tissue." It was for this reason that the case was reported (Blanshard, 1953) as one of isolated diffuse myocarditis, but we think this diagnosis pays too little attention to the clinical picture and family history.

There is no evidence of endocarditis or of myocardial changes suggestive of rheumatic disease. The distribution of the lesions is unlike that described in subendocardial fibrosis (Gray, 1951). Although there is medial thickening of the coronary arteries, coronary occlusion is not demonstrated and the myocardial changes are disproportionately great. Cellular infiltration of the isolated myocardium is generally minimal and unlike the typical findings in isolated myocarditis or in cardiovascular collagenosis (Becker et al., 1953).

Glycogen could not be demonstrated by the periodic Schiff technique in any part of the heart of Case 3. The necropsy was performed 24 hours after death and the left ventricle was fixed unopened, two factors that might account for loss of glycogen before staining; but the right ventricle was opened at the necropsy and fixation was rapid so glycogen should have been demonstrated had it been present. Glycogen storage disease affecting the heart alone has been reported (Pompe, 1932; Abbott, 1909; von Crevald and van der Linde, 1939) but all the patients have died within the first four years of life.

Though familial cardiomegaly is generally unnoticed till early adult life it seems more likely that there is a genetic cause. The evidence is scanty but suggestive of its inheritance as a dominant Mendelian character.

\section{SUMMARY}

Two more families with cardiomegaly unassociated with any other familial disease are reported. In one a mother and son died young with very large hearts and bundle-branch block. In the other, three members in three generations had large hearts and a slow heart rate, two with heart block and the third with sinus bradycardia and bundle-branch block. None of the accepted causes of cardiac enlargement was present. Several other members of both families died at an early age or had a history of heart disease. 
Although familial cardiomegaly is generally associated with early death, one of our patients is still living at the age of 66 years.

The morbid anatomy and histology of two cases are described.

We are greatly indebted to Dr. Geoffrey Konstam for giving us the information about the necropsy of Case 1 and about the report of this case by Blanshard.

\section{REFERENCES}

Abbott, M. E. (1909). Congenital Cardiac Disease. Philadelphia.

Becker, B. J. P., Chatgidakis, C. B., and van Lingen, B. (1953). Circulation, 7, 345.

Blanshard, T. P. (1953). Brit. Heart J., 15, 453.

Ellis, R. W. B., and Payne, W. W. (1936). Quart J. Med., 29, 387.

Elster, S. K., Horn, H., and Tuchman, L. R. (1955). Amer. J. Med., 18, 900.

Evans, W. (1949). Brit. Heart J., 11, 68.

- - , and Wright, G. (1942). Brit. Heart J., 4, 91.

Gaunt, R. T., and Lecutier, M. A. (1956). Brit. Heart J., 18, 251.

Gray, I. R. (1951). Brit. Heart J., 13, 387.

Paulley, J. W., Jones, R., Green, W. P. D., and Kane, E. P. (1956). Brit. Heart J., $18,55$.

Pompe, J. C. (1932). Med. Tigd. Gemeesk., 76, 304.

Russell, D. S. (1946). J. Path. Bact., 58, 739.

von Creveld, S., and van der Linde, H. M. (1939). Arch. Dis. Childh., 14, 14.

von Gierke, E. (1929). Beitr. path. Anat., 82, 497. 